\title{
A convenient route to synthesize hexagonal pillar shaped ZnO nanoneedles via CTAB surfactant
}

\section{K. Kaviyarasu, Prem Anand Devarajan*}

\author{
Department of Physics, St. Xavier's College, Palayamkottai, 627002 India
}

*Corresponding author. Tel/Fax: (+91) 44-27663864; Email: dpremanand@yahoo.co.in

Received: 17 October 2012, Revised: 24 November 2012 and Accepted: 11 December 2012

\section{ABSTRACT}

In this work we report the successful formation of hexagonal pillar shaped $\mathrm{ZnO}$ nanoneedles with high yield and by using simple cheap method with CTAB as the surfactant. SEM and TEM microscopic observation revealed that the ZnO nanorods were smooth and uniform throughout their length and the functional groups in the molecule were identified by FTIR analysis. PL properties of $\mathrm{ZnO}$ nannorods were found to be dependent on the growth condition and the resultant morphology revealed that $\mathrm{ZnO}$ nanorods were highly transparent in the visible region. . Copyright (C 2013 VBRI press.

Keywords: Characterization; nanostructures; X-ray diffraction; surface structure; hydrothermal crystal growth; oxides; nanoneedles; photoluminescence; inorganic compounds.

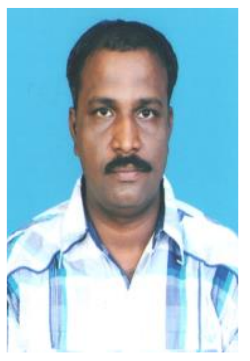

D. Prem Anand is a faculty at the Department of Physics, St. Xavier's College (Autonomous), Palayamkottai, Tirunelveli, Tamil Nadu. Just after completed his doctoral degree from the University of Madras, he joined as an Assistant Professor in St. .Xavier's College. In his academic carrier, he has published over 42 articles in the field of crystal growth and nanomaterial's synthesis. His areas of interest include Non linear optics, crystal growth, Nanomaterials, drug delivery design and supramolecular assembly.

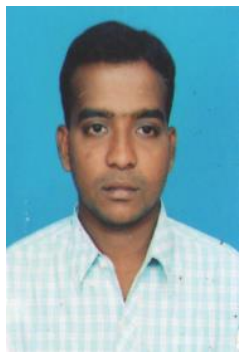

K. Kaviyarasu did his Post Graduate in Physics at Loyola College, Chennai affiliated to University of Madras. At present he is a Research Scholar at Department of Physics, St. Xavier's College (Autonomous), Palayamkottai, Tirunelveli, Tamil Nadu. His areas of interests include Nanomaterial's synthesis, characterization and fabrication of nanomaterial's for drug delivery design.

\section{Introduction}

Zinc oxide $(\mathrm{ZnO})$ is a well known semiconductor for its wide band gap $(3.37 \mathrm{eV})$ and high excition binding energy of $60 \mathrm{meV}$ at room temperature. It possesses unique optical, acoustical and electronic properties which initiates wide interest in the scientific arena [1-4]. Recently optical wave confining and lagging action has been demonstrated in $\mathrm{ZnS}$ and $\mathrm{ZnO}$ nanorods [5-11]. A theoretical predication of the possibility of room temperature ferromagnetism has also stimulated research interest in the field of diluted magnetic semiconductors (DMSc). It is possible to create nanorods and nanoneedles which are ferromagnetic at room temperature and if it becomes possible to increase their magnetization by several orders of magnitude and if it becomes possible to either flip to direction of magnetization by external field, then $\mathrm{ZnO}$ nanoneedles may be used as nanosized read/write heads for magnetic data storage. As a result, searching a new methodology to synthesize aligned $\mathrm{ZnO}$ nanoneedles structure is of great importance for fundamental study and practical applications. As a consequence it possess unique optical, acoustical and electronic properties which stimulates wide range interest in its potential applications. A particularly striking recent observation is that of room temperature lasing action in $\mathrm{ZnO}$ nanorod arrays highlighting the prospects that the functional design of $\mathrm{ZnO}$ nanostructure in a highly oriented and an ordered array is of crucial importance for the development of device in practical applications with high performance [12-18] Up to now 
various methods [19-27] were utilized to fabricate $\mathrm{ZnO}$ nanorods. Among these methods the hydrothermal method is environmental friendly with large area deposition, low synthesis temperature and low production cost. Zinc oxide particles of various morphologies including nanorods, whiskers and nanowires were successfully prepared [2833]. The $\mathrm{ZnO}$ nanoparticles reported were synthesized at higher temperature with sophisticated instruments, expensive chemicals and complex reaction procedures. This article presents the fabrication of hexagonal pillar shaped $\mathrm{ZnO}$ nanoneedles via $\mathrm{CTAB}$ as a cationic surfactant. The synthesized products are highly crystalline and exhibits good structural and chemical properties providing a cost effective and a convenient route to obtain large quantities of Zinc oxide nanostructures. However, growth technique usually expensive, the choice of substrate restricted, complex process control and high temperature are unfavourable for an industrialized process. Hence we have used CTAB surfactant to overcome these limitations. There are advantages to use this surfactant i.e. the ordered $\mathrm{ZnO}$ nanoneedles are synthesized by controlling the density of the nanoparticles distribution which promotes the growth arrangement in a cheaper way to get similar structure of other $\mathrm{ZnO}$ compounds. Taking all these factors into consideration the process of study has been focused and the investigation of the relationship between wet chemical conditions size and morphology of the high aspect ratio products. The main objective of the present work is to synthesize wurtzite $\mathrm{ZnO}$ nanoneedles, because the lack of centre of symmetry in wurtzite results in strong piezoelectric and pyroelectric properties which is a key property in building electromechanical coupled sensors and transducers. The crystalline structure and surface morphology of $\mathrm{ZnO}$ nanoneedles were assessed by X-ray powder diffraction (XRPD), Scanning electron microscopy (SEM), Transmission electron microscopy (TEM) analyses. The optical performances of the $\mathrm{ZnO}$ nanoneedles were characterized by photoluminescence (PL) studies. The functional groups in $\mathrm{ZnO}$ nanostructure was ascertained by Fourier transform infrared spectroscopy (FTIR) analysis.

\section{Experimental}

\section{Materials and methods}

All chemicals were analytical grade (AR) and used as purchased without further purification. Zinc Acetate $[\mathrm{Zn}(\mathrm{Ac})]_{2} .2 \mathrm{H}_{2} \mathrm{O}$ (Zinc source), cetyltriethylammonium bromide (CTAB) and ethanol were purchased from EMerck Company (99.99\%). The crystalline phase and orientation of products were identified using X-ray powder diffraction (XRPD) technique using a Riga KuD/max - RB diffractometer with Cuk $\alpha$ radiation $\lambda=1.54056 \AA$ under 40 $\mathrm{Kv}, \quad 40 \mathrm{~mA}$ and scan rate of $10^{\circ} \mathrm{min}^{-1}$. The functional groups in $\mathrm{ZnO}$ nanonedles were graphed by Fourier transform infrared spectroscopy (FTIR). The spectrum was recorded with a (Brukker IFS - 66V) spectrometer. Photoluminescence (PL) measurements of the as synthesized product were carried out an F-4500 KIMON Fluorescence spectrophotometer at room temperature with a Xe lamp as the excited light source the excitation wavelength was $397 \mathrm{~nm}$. The morphology and microstructure were examined using scanning electron microscopy (SEM) performed on a (JSM - 6700F) with an acceleration voltage of $16.0 \mathrm{kV}$ and a high resolution transmission electron microscope (TEM), (Philips CM12).

\section{Experimental details}

In a typical synthesis, $150 \mathrm{ml}$ of $1 \mathrm{M}$ Zinc acetate aqueous solution was mixed with $25 \mathrm{ml}$ of $1 \mathrm{M}$ ethanol and the resulting mixture was stirred thoroughly using a magnetic stirrer. The precursor of white precipitate was obtained. The as-obtained white precipitate was collected and washed with deionised water twice. Nearly $2.5 \mathrm{~g}$ of precursor was added to $50 \mathrm{ml}$ of $0.5 \mathrm{M}$ concentration of CTAB solution, to get a precipitated liquid. Then the above solution was transferred to Teflon lined autoclave at $240^{\circ} \mathrm{C}$ in an oven for $24 \mathrm{hrs}$. After $24 \mathrm{hrs}$ white crystalline product was collected and thoroughly washed with ethanol twice. Supported by the above analyses the whole reaction process may be represented by the following equation. Thus the Zinc acetate ion was transferred to zinc oxide when CTAB was introduced into the solution, Thus CTAB acts as the dissolution of the formed Zinc oxide. Based on the above equation under present wet chemical condition, then this reaction would gradually condense into solid phase $\mathrm{ZnO}$ and seeds (nanoneedles) which appeared in the heating solution through a homogeneous nucleation. The nanoneedles grew longer and shaped into separate nanoneedles. Hence CTAB may be more suitable for the formation of long and uniform $\mathrm{ZnO}$ nanoneedles due to its chain like structure. We also came to know that the length of CTAB had little influence only on the shape of the products. The reaction process is

\section{$\mathrm{Zn}\left(\mathrm{CH}_{3} \mathrm{COO}\right)_{2} \cdot 2 \mathrm{H}_{2} \mathrm{O}+2 \mathrm{C}_{2} \mathrm{H}_{5} \mathrm{OH} \longrightarrow \mathrm{ZnO}+2 \mathrm{CH}_{3}-$ $\mathrm{CO}-\mathrm{C}_{2} \mathrm{H}_{5}$}

\section{Results and discussion}

\section{$X$-ray powder diffraction analysis}

Fig. 1 shows the XRPD pattern of the $\mathrm{ZnO}$ nano samples. The diffraction peaks are in good agreement with a typical wurtzite type $\mathrm{ZnO}$ crystal (hexagonal, $\mathrm{P}_{3} \mathrm{mc}$, JCPDS No. 36-1451) and no impurity phase was detected. The sharpness of the peaks reveals a high degree of crystallinity of the as-synthesized $\mathrm{ZnO}$ samples. No peaks from either $\mathrm{ZnO}$ in other phases or impurities were observed. It is well noted that the (101) diffraction peak dominates the spectra of all the $\mathrm{ZnO}$ nanoneedles synthesized in this study and other diffraction peaks are normal, ascertaining that the well aligned (101) oriented $\mathrm{ZnO}$ nanoneedles were harvested which is in good consistent with the SEM micrograph, and also the highest peak assigned to (1011) plane indicating wurtzite structure [34].

\section{FTIR spectroscopy}

Fig. 2 shows the FTIR spectra of the as synthesized $\mathrm{ZnO}$ nanoneedles in the wavelength range of $4000-400 \mathrm{~cm}^{-1}$ A peak at $3419 \mathrm{~cm}^{-1}$ is attributed to $\mathrm{O}-\mathrm{H}$ group. The peak at $1725 \mathrm{~cm}^{-1}$ is assigned to asymmetric COO- stretching vibration modes of acetate group. The band appearing at $1371 \mathrm{~cm}^{-1}$ is attributed to the symmetric COO- stretching vibration mode of acetate group. The peak at $817 \mathrm{~cm}^{-1}$ is 


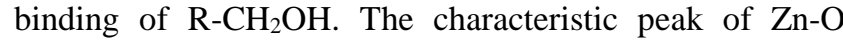
bond is observed at $488 \mathrm{~cm}^{-1}$ [35]. Thus IR studies indicate that $\mathrm{ZnO}$ peaks were formed due to the direct decomposition of Zinc acetate.

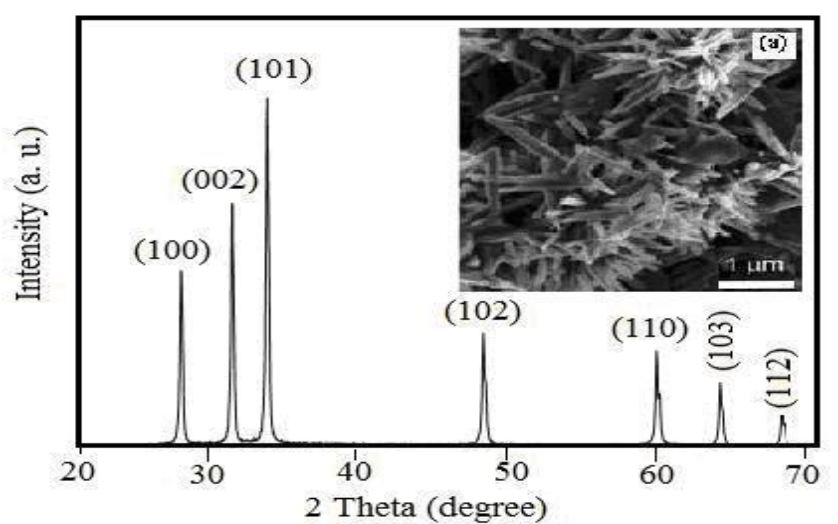

Fig. 1. XRPD pattern of $\mathrm{ZnO}$ nanoneedles.

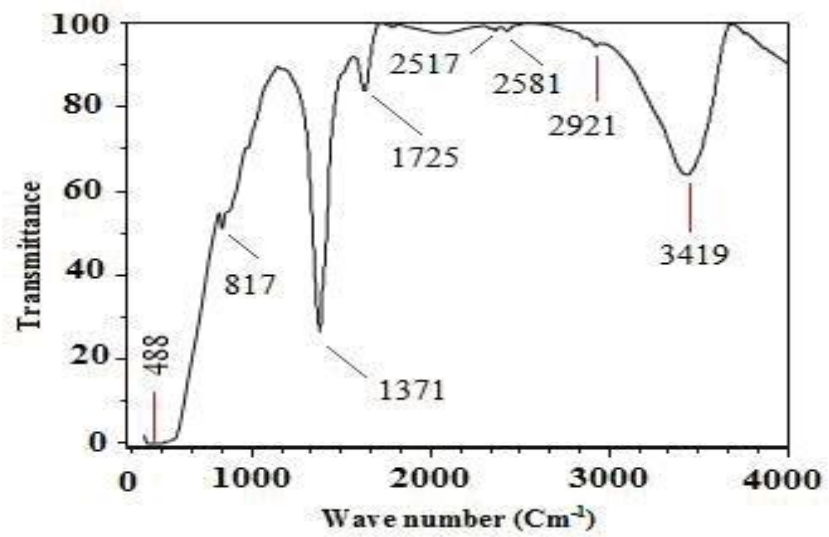

Fig. 2. FTIR spectrum of $\mathrm{ZnO}$ nanoneedles.

\section{Scanning electron microscope}

Fig. 3 (a-c) depicts SEM images of as synthesized $\mathrm{ZnO}$ nanoneedles with different magnification respectively. From the images it is clear that the smooth solid hexagonal rods were observed. Hence it can be said that the product from solvothermal synthesis in ethanol was $\mathrm{ZnO}$ nanoneedles and it is invariably longer due to the presence of ethanol [36].
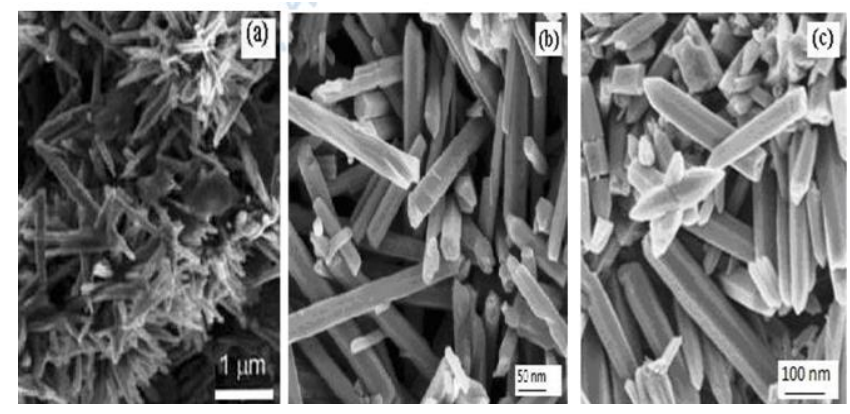

Fig. 3. SEM photographs of $\mathrm{ZnO}$ nanoneedles.

\section{Transmission electron microscope}

Fig. 4 shows the TEM image of as synthesized $\mathrm{ZnO}$ nanoneedles. As seen from the figure, it is clear that only the polygranules are visible and these granules congregate. A special granule indicated by a circle shows the general uniform is hexagonal. The particles are nearly spherical and remains assembled together with the long grain and the adjacent particle coalesces together forming spherical particles [37]. Thus the result is consistent with the SEM micrographs and XRPD studies.

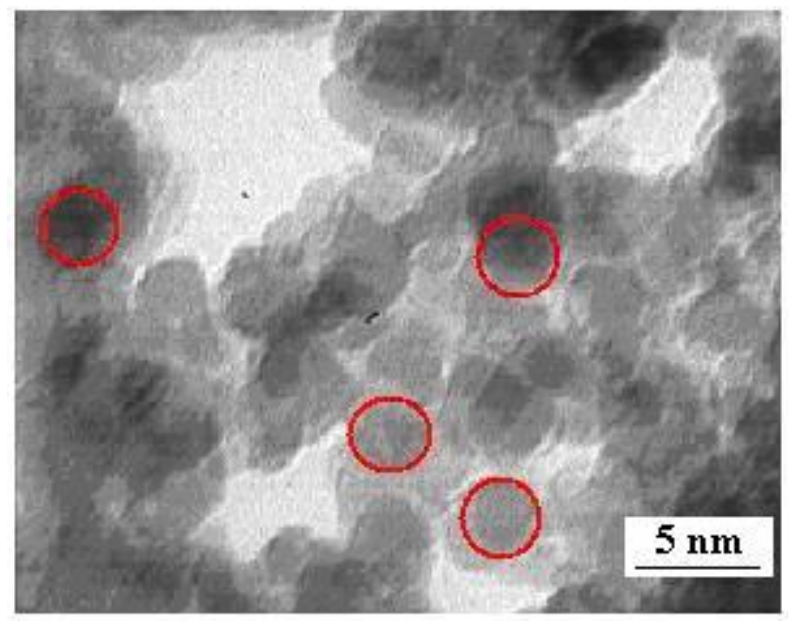

Fig. 4. TEM photograph of $\mathrm{ZnO}$ nanoneedles.

\section{Photoluminescence spectroscopy}

Fig. 5 shows the PL spectrum of the as synthesized $\mathrm{ZnO}$ nanoneedles. The spectrum has wide broader peak ranging from 390 to $400 \mathrm{~nm}$ and a sharp one centered on at $397 \mathrm{~nm}$ which is in tune with Wang, Peng and Wu et al [38-40]. The blue luminescence may be considered to be result of radioactive recombination of photo generated holes within singularly ionized oxygen vacancies. In our case, no green light emission peak was found implying $\mathrm{ZnO}$ nanoneedles has very low concentration of oxygen vacancies. In our study, based on calculation, the energy $(3.07 \mathrm{eV})$ of the UV emission peaked at $397 \mathrm{~nm}$ is well consistent with the energy interval from the bottom of the conduction band to $\mathrm{V}_{\mathrm{zn}}$ level $(3.06 \mathrm{eV})$ [41]. Hence it may be well said that the $\mathrm{UV}$ emission of needle like $\mathrm{ZnO}$ nanostructure in our work is due to zinc vacancy.

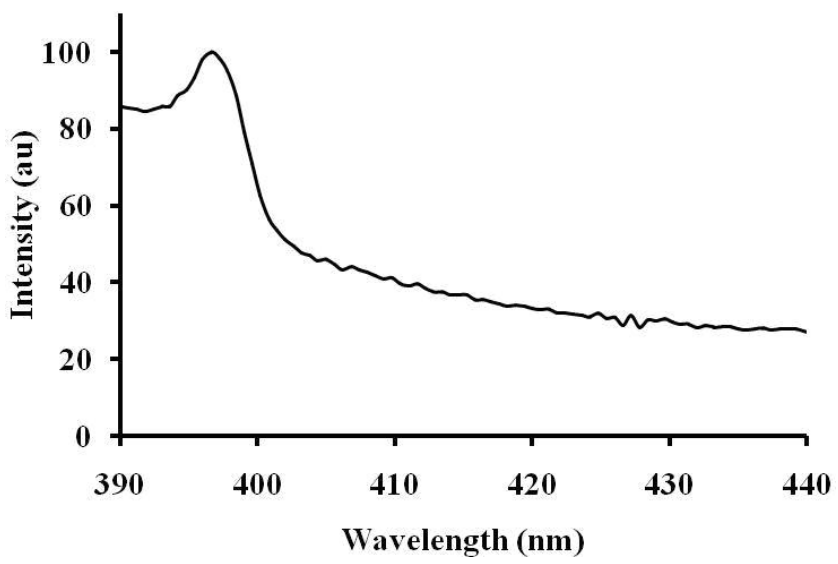

Fig. 5. PL spectrum of $\mathrm{ZnO}$ Nanoneedles

\section{Conclusion}

In summary, we have developed, a simple and a cost effective method to synthesize hexagonal pillar shaped 
nanorods under the assistance of CTAB surfactant. As identified by XRPD analysis, the $\mathrm{ZnO}$ nanoneedles are single crystalline free from defects possessing wurtzite hexagonal phase. Additionally FTIR spectrum also shows good chemical properties of zinc oxide. The proposed work is supportive based an SEM and TEM observation. The PL studies reveal a sharp UV emission peak central at $397 \mathrm{~nm}$ at room temperature. We firmly believe that hexagonal $\mathrm{ZnO}$ nanorods will pave a way for the development of nanoscale electronics, flexible solar cells, gas sensing applications and optics.

\section{Acknowledgements}

One of the authors (K. Kaviyarasu) would like to thank Dr. S. Paulraj, Head of the Department of Physics, St. Xavier's College, Palayamkottai for his constant support, help and encouragement.

\section{Reference}

1. Xia, Y,; Yang, P.; Sun, P,; Wu, Y,; Mayers, B,; Gates, B,; Yin, Y,;. Kim, F,; Yan, H, Adv. Mater. 2003, 15, 353. DOI: $\underline{10.1002 / \text { adma. } 200390087}$

2. Hiramatsu, M,; Imaeda, K,; Horio, N,; Nawata, M, J. Vac. Sci. Technol. 1998, 16, 669 .

DOI: $10.1116 / 1.581085$

3. Zapier, J.A.; Jiang, Y.; . Meng, X.M.; Chen, W.; Au, I.C.K.; Lifshitz, Y.; Lee, S.T. Appl Phys Lett. 2004, 84, 1189. DOI: $10.1021 / \mathrm{nl} 049169 \mathrm{r}$

4. Vagssieres, L. Adv Mater. 2003, 15, 464. DOI: $10.1021 / \mathrm{jp} 051204 \mathrm{a}$

5. Huang, M.H.; Mao, S.; Feick, H.; Yan, H.; Wue, Y.; kind, H.; Weber, E.; Russo, R.; Yang, P. Science, 2001, 292, 1897. DOI: $10.1039 / \mathrm{A} 902335 \mathrm{~F}$

6. Zhou, G.; Xian, W.; Jian, L.; Shanshan, Y.; Yanyan, D.; Zhenzhoe, W.; Yuan, H. Solid State Chem. 2006, 179, 1984. DOI: $10.1107 /$ S1600536808033539

7. Okada, T,; Agung, B.H,; Nakata, Y, J. App. Phy. A, 2004, 79, 4 DOI: $10.1016 / j . c p l e t t .2007 .09 .018$

8. Qingwei, L,; Jiming, B,; Jingchang, S,; Jingwei, W,; Yingmin, L; Kaitong, S,; Dongqi, Y, J. Appl. Surf. Sci. 2010, 256, 1698. DOI: $10.1021 /$ ic $102097 \mathrm{q}$

9. Prabakar, K,; Kim, C,; Lee, C,; J. Cryst. Res. Technol. 2005, 40, 1150.

DOI: 10.1143 /APEX.5.012603

10. Myo Than Htay,; Yoshio Hashimoto,; Kentaro Ito, Jpn. J. Appl. Phys. 2007, 46, 440.

DOI: $\underline{10.1143 / J J A P .46 .440}$

11. Shah, M.H,; Tokeer, A,; "Principles of nanosize and nanotechnology" Narosa publishing House, New Delhi, ISBN 77881-8487-072-5.

DOI: $10.1002 / 9781118311974$

12. Namasi Karkare, I.K,; "Nanotechnology fundamentals and applications" International publishing House Pvt Limited, New Delhi. ISBN 978-81-89866-99-0.

DOI: $10.1142 / 6788001879032$

13. Charles P. Poole,; Jr,; Franck \& Owens, J,; "Introduction to nanotechnology" Wiley India Pvt Limited, New Delhi, ISBN 978-81265-1099-3.

DOI: $10.18902 / 961382398450143$

14. Tiwari, A,; Mishra, A,; Kobayashi, K,; Turner, H, Intelligent Nanomaterials, Wiley-Scrivener Publishing LLC, USA, ISBN 97804-709387-99, 2012. DOI: $10.1002 / 9781118311974$.

15. Chien-Te Hsieh, Shu-Ying Yang, Jia-Yi Lin, J. Thin Solid Film, 2010, 41, 4884.

DOI: $10.1016 / j . t s f .2010 .03 .081$,

16. Seong-Jong Kim,; Han-Hyoung Kim,; Joo-Beom Kwon,; Jong-Geun Lee,; Beom-Hoan O,; Seung Gol Lee,; El-Hang Lee,; Se-Geun Park, Microelec Eng, 2010, 87, 1534.

DOI: $10.1016 /$ j.mee.2009.11.033

17. Zhang, Y,; Dai, Y,; Huang, Y,; Zhou, C, Univ. Sci. Technol, Beijing, 2004, $11,23$.

DOI: $10.1021 / \mathrm{ie} 061396 \mathrm{~b}$

18. Li, J.Y,; Chen, X.L,; He, M,; Qiao, Z.Y, J. Cry. Grow. 2001, 23, 35.
DOI: $10.1016 / \mathrm{S} 0022-0248(01) 02164-9$

19. Sue, K,; Kiruma, K,; Yamamoto, M,; Arai, K, J. Mater. Lett. 2004, 58,3350 .

DOI: $10.3390 / \mathrm{ma} 3073794$

20. Hu, H.Q,; Ma, X.L,; Xie, X.Y,; Wong, N.B, J. Chem. Phys. Lett. 2001, 344. 97. DOI: $10.1021 / \mathrm{jp} 0009305$

21. Liu, Y,; Liu, Z,; Wang, G, J. Crys. Grow. 2003, 252, 213. DOI: $10.1016 / \mathrm{S} 0022-0248(02) 02518-6$,

22. Lyu, S.C,; Zhang, Y,; Ruh, H,; Lee, H.J. J. Chem. Phys. Lett. 2002, $366,134$.

DOI: $10.1143 / \mathrm{JJAP} .48 .08 \mathrm{HJ} 03$

23. Haiyan, X,; Hao, W, Int. Ceram. 2004, 30, 93. DOI: $10.1016 / \mathrm{S} 0272-8842(03) 00069-5$

24. Bitenc, M,; Orel, X.C, Mater. Res. Bull. 2009, 44, 381. DOI: $10.1039 / \mathrm{c} 0 \mathrm{jm} 02823 \mathrm{a}$

25. Bitenc, M,; Podbrscek, P,; Orel, Z.C, J. Cry. Grow. Des. 2009, 9 , 997.

DOI: $10.1111 / \mathrm{j} .1151-2916.1989 . t b 06237$

26. Hang,; jurisic,; Aleksandra,; Liu,; Zheng Tong,; Li,; J. Phy. Chem. Sol. 2008, 69, 353 .

DOI: $10.1016 /$ j.jpcs.2007.07.029

27. Qiang Li,; Yiqing Chen,; Xinhua Zhang,; Yong Su, J. Phy. Chem. Sol. 2009, 70, 1482.

DOI: $10.1016 / j . j p c s .2008 .09 .012$

28. Zhou, X.F,; Hu, X.L,; Chen, Y,; Shang, H.Y, Mater. Res. Bull. 2008, 43, 2790. DOI: $10.1016 /$ j.apsusc. 2008.12 .067

29. Pengli Zhu,; Jingwei Zhang,; Zhishen,; Zhijun Zhang,; Cry. Grow. Des. 2008, 8, 3148

DOI: $10.1021 / \mathrm{jp} 802619$

30. Hsin-Ming Cheng,; Hsu-Cheng Hsu,; Shiow-Lian Chen,; Wen-Ti Wu,; Chih-Chun Kao,; Li-Jiaun Lin,; Wen-Feng Hsieh, J. Cry. Grow. 2005, 277, 192.

DOI: $10.1016 /$ j.apsusc.2008.12.067

31. Qiu, Y.F,; Yang, S, Adv. Funct. Mater. 2007, 17, 1345. DOI: $10.1002 / \mathrm{adfm} .200601128$

32. Zhang, H,; Shen, L; Guo, S, J. Phy. Chem. C, 2007, 111, 12939. DOI: $10.1016 /$ j.apsusc. 2008.12 .067

33. Ni, Y,; Wu, G,; Zhang, X,; Cao, X,; Yang, Z, Mater. Res. Bull. 2008, 43,2919

DOI: $\underline{10.1016 / j . s n b .2008 .04 .024}$

34. Neha Singh,; Padmini Pandey,; Fozia, Z,; Haque, H, Adv. Funct. Mater. 2012, 123, 1340.

DOI: $10.1021 / \mathrm{cr} 8003983$

35. Rizwan Wahab,; Young-Soon Kim,; Hyung-Shik Shin, Cur. Appl. Phy. 2011, 11, 334

DOI: $10.1016 /$ j.cap.2010.07.030

36. Tonto, P,; Mekasuwandumrong, O,; Phatanasri, S,; Pavarajarn, V, Cer. Int. 2008, 34, 57.

DOI: $10.1016 / j . c e r a m i n t .2006 .08 .003$

37. Jayakumar, O.D,; Sudarsan, V,; Sudakar, C,; Naik, R,; Vasta, R.K, Tyagi, A.K, Scri. Materi. 2010, 62, 662.

DOI: $10.1166 / \mathrm{nnl} .2011 .1133$

38. Wang Jinmin,; Gao Lian, J. Cry. Grow. 2004, 262, 290 DOI: $10.1021 / \mathrm{cg} 900481 \mathrm{~m}$

39. Peng, X.P,; Zang, H,; Wang, H.G,; Xu, J.G,; Wang, Y.Y, J. Lumin. 2008, 128, 328 DOI: $10.1016 /$ j.saa.2011.08.038

40. Wu, D.W,; Yang, M,; Huang, Z.B,; Yin, G.F,; Liao, X.M,; Kang, Y.Q,; Chen, X.F,; Wang, H, J. Coll. Inter. Sci. 2009, 330, 380. DOI: $10.1016 /$ j.jcis.2010.05.036

41. Xua, C.L,; Qin, D.H,; Lia, H,; Guoa, Y,; Xub, T,; Lia, H.L, Mater Lett. 2004, 58, 3976.

DOI: $\underline{10.1016 / j . \mathrm{mseb} .2005 .02 .065}$
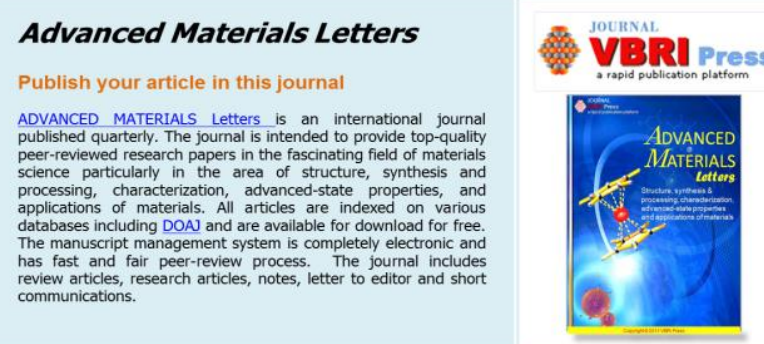